\title{
Financial capacity building for NGO sustainability
}

John H. Bratt

Rick Homan

Barbara Janowitz

James R. Foreit

Population Council

Follow this and additional works at: https://knowledgecommons.popcouncil.org/departments_sbsr-rh

Part of the Demography, Population, and Ecology Commons, Family, Life Course, and Society Commons, Gender and Sexuality Commons, International Public Health Commons, Maternal and Child Health Commons, Medicine and Health Commons, and the Women's Health Commons How does access to this work benefit you? Let us know!

\section{Recommended Citation}

Bratt, John H., Rick Homan, Barbara Janowitz, and James R. Foreit. 2008. "Financial capacity building for NGO sustainability," FRONTIERS Program Brief no. 12. Washington, DC: Population Council. 


\section{Financial Capacity Building for NGO Sustainability}

nternational donors have partnered with non-governmental organizations (NGOs) for the delivery of family planning and reproductive health services since the 1960s. They found NGOs to be reliable and effective partners in service delivery during the years before public-sector programs were established. Throughout the developing world, NGOs also have been important centers of innovation for clinical, training, and service delivery research. More recently, concerns about poorly targeted subsidies in the public sector have highlighted the role that NGOs can play to reduce pressure on public-sector resources-for example, by providing care for clients who can afford to pay for services, or by providing or managing services through private-public-sector partnerships.

While demand for family planning and reproductive health services is increasing worldwide, a number of recent trends threaten the financial sustainability of donorsupported NGOs that provide these services. First, the U.S. Agency for International Development (USAID)—-the

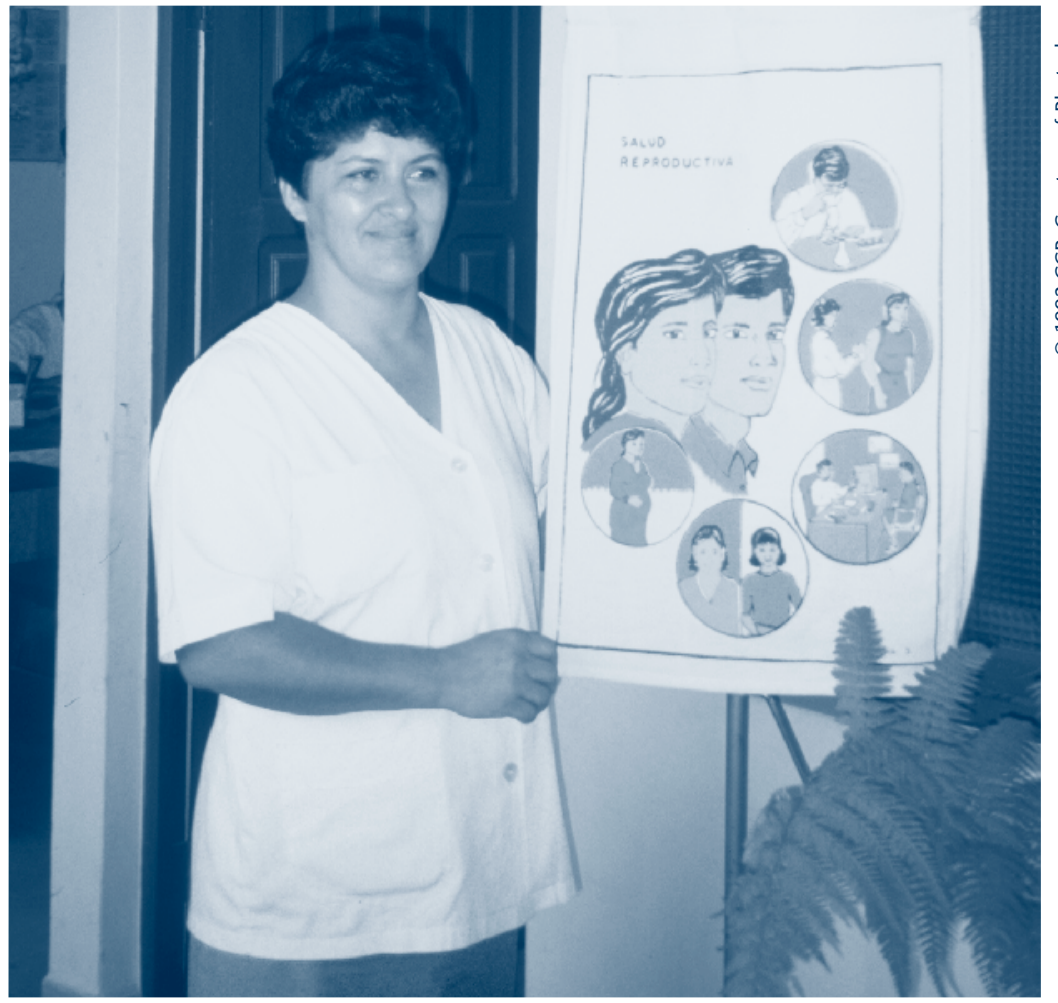

A family planning educator at Bolivia's Prosalud, one of the NGOs that worked on sustainability projects with FRONTIERS.

largest donor to family planning programs-has seen its funding for population assistance decline in real terms since 1995 (PAI 2008). Part of this decline is related to the concurrent increase in funding for HIV/AIDS and other infectious diseases, leaving fewer resources for family planning and reproductive health. A second reason is the growth of governmentfunded programs that provide these services for low-income clients, which reduced the need for NGOs to focus their programs entirely on the poor. Health sector reform has created opportunities for NGOs via public-private partnerships in some countries, but sustained public-sector support is unlikely given limited economic growth in domestic economies and competition from other health priorities.

NGOs need financial analysis skills to progress toward financial sustainability.

- Financial capacity building must include and ensure support from managers.

- NGOs seeking financial sustainability must become aware of emerging markets and opportunities. 
Faced with these challenges, many NGOs ceased operations, while others struggled to reengineer themselves to produce health services for which either clients or donors are willing to pay. Long-term sustainability of NGOs may require that they become largely financially self-reliant, but few NGOs have the skills in costing, break-even analysis, and market research to reduce costs and increase income. This Program Brief describes the Financial Sustainability Capacity Building Initiative (FSCBI), a multi-year global effort by the Frontiers in Reproductive Health Program (FRONTIERS) in partnership with Family Health International (FHI). The objective of FSCBI was to build NGO capacity to conduct economics-related operations research (OR) to improve financial sustainability. This brief reviews key elements of the capacity building model, explains its implementation, and discusses lessons learned about building capacity to conduct financial sustainability analysis.

\begin{tabular}{|c|c|}
\hline Contents & \\
\hline $\begin{array}{l}\text { Developing OR on } \\
\text { sustainability }\end{array}$ & 3 \\
\hline The FSCBI & 3 \\
\hline Lessons learned & 6 \\
\hline Conclusions & 10 \\
\hline References & 11 \\
\hline
\end{tabular}

Financial sustainability is a state in which an institution has a reasonable expectation of covering its costs for the foreseeable future through a combination of donor funding and locally generated income. When donor funding declines, an organization may work to return to financial sustainability through some combination of cost control and income generation.

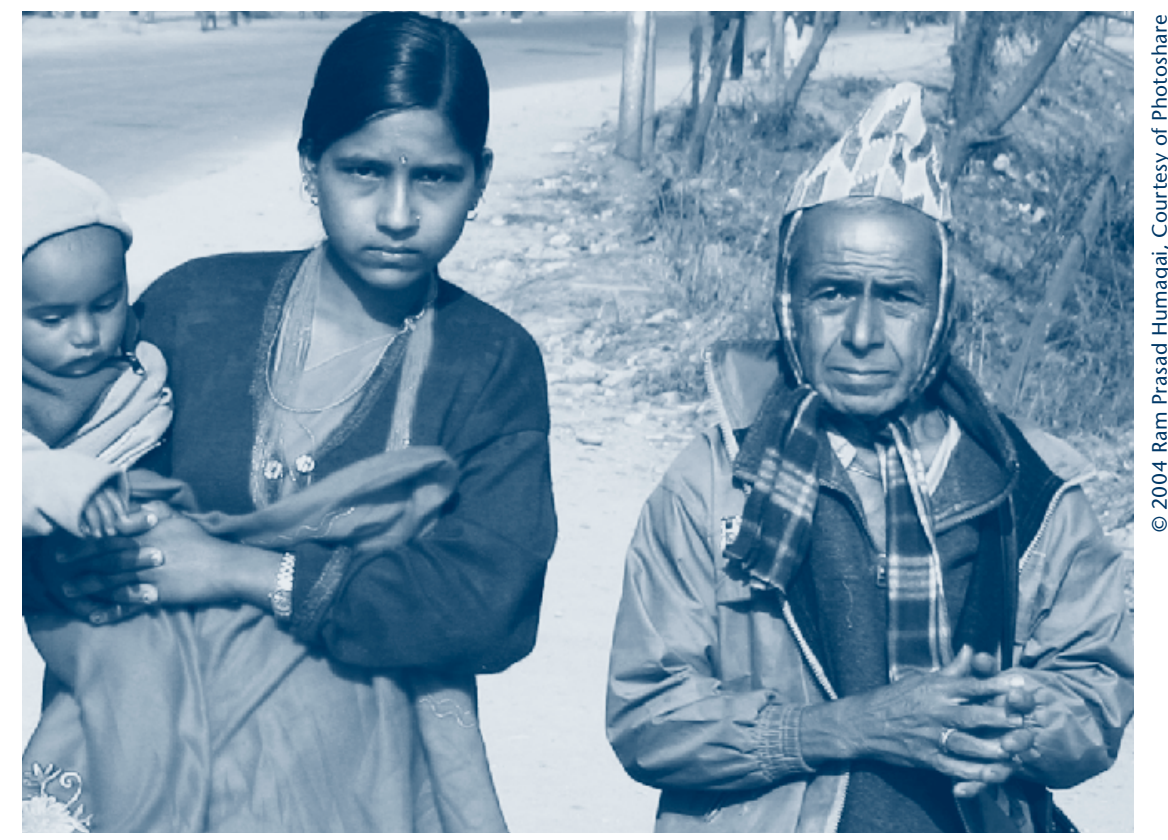

The Chhetrapati Family Welfare Center provides reproductive health services to clients such as this 14-year-old mother, accompanied by her father. 


\section{Developing OR on sustainability}

As concerns about financial sustainability of USAID-funded NGOs emerged in the late 1980s, USAID cooperating agencies and others began using OR to help NGOs find solutions to the problems of cost control and income generation. The successful multiyear collaboration between the Population Council's INOPAL project $^{1}$ and the Medical Center for Orientation in Family Planning (known by its Spanish acronym CEMOPLAF), an Ecuadorian NGO, demonstrated the potential of OR to assist such organizations to reduce financial dependence on donors (Bratt et al. 1998).

INOPAL and CEMOPLAF carried out a series of OR studies that contributed to improvements in financial sustainability. These included: (1) measuring costs of programs and individual services; (2) measuring

${ }^{1}$ INOPAL (INvestigación OPerativa y Asistencia Técnica en Planifación Familiar y Salud Materna en América Latina y el Caribe, or OR and Technical Assistance in Family Planning and Maternal Health in Latin America and the Caribbean) was the regional OR project for Latin America and the Caribbean (LAC). In 1998 INOPAL joined with the two other USAID-funded regional OR projects to become the global FRONTIERS Program in OR. FHI collaborated informally with INOPAL on sustainability-related OR and was a partner for economic evaluation on FRONTIERS. elasticity of demand for services; (3) measuring client economic status; and (4) evaluating the impact of sustainability-related interventions on institutional revenues, costs, client volume, and clients' socioeconomic characteristics. When USAID specified that capacity building and economic evaluation would be areas of special emphasis for the FRONTIERS Program, it was a natural step for FRONTIERS to create an initiative to strengthen sustainability-related OR skills in NGOs worldwide.

\section{The FSCBI}

Beginning in 1999, and building on the success of the INOPAL-CEMOPLAF experience, FRONTIERS and FHI developed the global FSCBI. FSCBI's overall goal was to build NGO skills in analytic techniques through a participatory research process focused on issues that were relevant to an institution's financial sustainability. Specific objectives of the FSCBI included the following:

- Testing a workshop model that combined classroom instruction with proposal development, research funding, and technical assistance.

- Orienting NGO participants, including researchers, financial managers, and administrators, on a set of basic research tools for assessing and improving financial sustainability
Frontiers in Reproductive Health Program Brief No. 12

Author: John H. Bratt, Barbara Janowitz, Rick Homan, and James Foreit

Editor: Stephanie Joyce

Design: Vincent Hughes Visualization We appreciate the assistance and contributions of the following reviewers: Ian Askew, Patricia Stephenson.

Suggested citation: Bratt, John H., Barbara Janowitz, Rick Homan, and James Foreit. 2008. "Financial capacity building for NGO sustainability," FRONTIERS Program Brief No. 12. Washington, DC: Population Council.

The photos on pages 1, 2, 7, 9, and 10 were selected from Photoshare at www.photoshare.org

The Frontiers in Reproductive Health Program (FRONTIERS) applies systematic research techniques to improve delivery of family planning and reproductive health services and influence related policies. FRONTIERS is funded by the U.S. Agency for International Development (USAID) and led by the Population Council in collaboration with Family Health International.

This publication is made possible by the generous support of the American people through the United States Agency for International Development (USAID) under the terms of Cooperative Agreement No. HRN-A-00-98-00012-00. The contents are the responsibility of the FRONTIERS Program and do not necessarily reflect the views of USAID or the United States Government.

(C) 2008 The Population Council, Inc.

This publication may be reproduced in whole or in part without permission of Population Council provided full source citation is given and the reproduction is not for commercial purposes.

ISSN 1546-6612 
Establishing long-term relationships between selected NGOs and FRONTIERS to conduct sustainability research and capacity-building activities.

\section{Selecting NGOs}

The FSCBI followed sustainability workshops in Ecuador (2002) and Kenya (2003). In each region, NGOs were brought together to discuss their current financial sustainability strategies, share experiences, and learn about potential opportunities. FRONTIERS and other agencies presented financial sustainability tools, such as the Population Council's willingness-to-pay survey technique ${ }^{2}$ and the business plan initiative developed by Management Sciences for Health. It was found that Latin American NGOs were conducting large numbers of sustainability activities, and that African NGOs were conducting only a few activities. The findings from these conferences led FRONTIERS to design a five-day sustainability workshop with a slightly different focus in each region (LAC, Africa, and eventually, West Asia). The workshops resulted in a total of

\footnotetext{
${ }^{2}$ Willingness-to-pay-surveys help managers to predict revenues by assessing clients' reaction to hypothetical changes in services prices. See Fleischman Foreit and Foreit 2004, online at http://www.popcouncil.org/pdfs/frontiers/Capacity_Bldg/ WTP_Manual.pdf
}

11 proposals (4 in Latin America, 3 in Africa, and 4 in Asia) that were funded by FRONTIERS. Topics included commercial marketing, break-even analyses of proposed activities, and cost analyses of current activities.

Following financial sustainability workshops in Ecuador and Kenya, FRONTIERS selected a group of NGOs to participate in week-long regional workshops in Africa (Accra, Ghana, March 2005), Asia (Jaipur, India, September 2005), and Latin America (La Paz, Bolivia, May 2004). Candidate NGOs had to be viable providers of family planning and reproductive health services, and preference was given to NGOs that produced a substantial share of services in their country or areas of operation. FRONTIERS also sought to include NGOs in which senior managers recognized problems with financial sustainability and agreed to commit staff resources to the FSCBI workshops and also to the OR projects developed at the workshops. Participating NGOs had to show that they had financial management and evaluation systems capable of monitoring processes and measuring results.

Using the above criteria, FRONTIERS selected four NGOs in each of the three regions and asked them to nominate several staff members to attend the workshop, prepare an OR proposal, and supervise implementation of the project. Attendees were required to have complementary skills and represent different functional areas within the NGO, including senior management and management of financial and information systems. Before attending the workshops, the NGOs were asked to prepare documentation describing their clientele, products or services provided, revenues and costs related to program activities, and descriptions of strategies, if any, addressing financial sustainability. ${ }^{3}$

\section{Workshop content}

The three one-week FSCBI workshops provided training on collecting and analyzing cost information (including service and market data, cost analysis, price-setting, cross-subsidization, ability to pay and willingness-topay techniques) and estimating costs and revenues of new products and services. The workshops began with didactic instruction and exercises and then shifted to preparation of OR proposals to address the sustainability problems of the participating NGOs. Facilitators recommended that organizations with minimal OR and financial management skills begin by conducting cost

\footnotetext{
${ }^{3}$ Course materials are available on the Population Council's website at http:// www.popcouncil.org/frontiers/capbldg/ cbcourses.html\#OR
} 
Box 1

\section{Conducting cost studies}

FRONTIERS' cost studies covered a range of topics, including analysis of operational costs; investigation of the market, including similar services provided by competitors; tests of new products or services; assessments of clients' willingness or ability to pay for services; and break-even analyses. Examples of typical projects follow.

Cost diagnostic: In 2005, FRONTIERS worked with four hospitals run by the Christian Health Association of Ghana (CHAG), which serves about 35 percent of Ghana's population, mostly in rural areas. CHAG managers who took the skill-building workshop determined average costs for services and identified the most expensive services. The information obtained in the $\$ 29,000$ study allowed CHAG to set prices and negotiate reimbursement under the national health insurance scheme (Boateng et al. 2006).

Sustainability diagnostic: Subsequently, CHAG conducted a sustainability diagnostic to measure whether tariff revenue from national health insurance would cover costs, and once again used the study findings to advocate for higher tariffs (Boateng, Surnye, Nyarko, and Bratt 2007).

Break-even analysis: FRONTIERS conducted OR to determine break-even points for the training center operated by The Aids Support Organization (TASO). The 10-month, $\$ 20,000$ project, which included a willingness-to-pay study, showed that low fees, high costs, and insufficient course size were the main threats to sustainability, and that increasing fees for courses could increase cost recovery from 50 percent to 60 percent, reducing TASO's dependence on donor support (Mugumya et al. 2006).

Income generation: In 2004, FRONTIERS conducted a 14-month, $\$ 28,000$ project with the Ghana Social Marketing Foundations Enterprises Ltd. (GSMFEL), one of Ghana's largest suppliers of contraceptives. GSMFEL sells some products at a profit, which subsidizes the sale of contraceptives at a lower price. The project tested the effect of training in complementary selling (asking customers whether they would like to buy a second project along with the original purchase) as a way of increasing sales of for-profit products. Findings showed no significant difference in sales between sites where training had or had not occurred, possibly because the additional products offered (nutritional supplements and lubricants) did not immediately address the relief of symptoms such as diarrhea. However, training in complementary sales was adopted as a routine practice for GSMFEL staff (Bruce et al. 2006). analyses and gathering information about their own clients and those of competitor organizations. More experienced NGOs conducted pricing studies, tests of the profitability of new products and services, and other kinds of market research. FSCBI guaranteed funding and technical assistance for only one project cycle but anticipated that NGOs with one successful OR experience would be motivated to engage in additional assessments, strategic planning, and testing of interventions to move their institutions closer to financial sustainability.

\section{Studies completed}

At the regional workshops, participants developed proposals for and subsequently conducted four main types of sustainabilityrelated OR studies (see Box 1 for examples of the duration, scope, and cost of selected studies).

Studies in the cost diagnostic category focused on measuring the average costs of services provided through clinics and hospitals; sustainability diagnostic studies looked at costs and also collected information on competing providers and measured clients' willingness to pay; break-even analysis examined the question of how many units of service or product needed to be sold in order to cover fixed and variable costs; and income generation studies measured the impact on revenues and costs of a variety of interventions designed to 
improve financial sustainability. Table 1 shows the types of studies conducted through FSCBI.

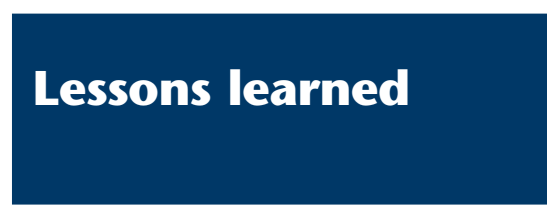

One-week workshops successfully catalyzed sustainabilityrelated $O R$, but momentum was difficult to maintain

All three regional workshops demonstrated the feasibility of assembling multidisciplinary teams of NGO staff, introducing a set of basic research tools to assess and improve financial sustainability, and helping the teams to write outlines of OR proposals to address problems with financial management and sustainability. Most NGO teams returned to their institutions with a draft proposal containing a problem statement, research objectives, a description of the research methodology, and a utilization plan. Their assignment was to continue working as a team to complete the proposal, with technical assistance from FRONTIERS and FHI via email. In most cases, completing the proposals to a standard acceptable to FRONTIERS and USAID took much longer than anticipated. The proposal had been the sole focus of team members during the workshop, but after the trainees returned to their regular jobs, other priorities took precedence. In several cases, this slower pace also carried over into project implementation.

\section{NGOs must conduct many projects to develop sustainable OR skills}

Despite difficulties in maintaining momentum, all participating NGOs produced proposals that were funded, and all but one of these projects resulted in a final report. However, institutionalization of OR skills learned in a workshop requires practice through subsequent application of the techniques and processes learned. This practice requires not only resources, but also commitment from senior managers who, given their many programmatic priorities, must be convinced that conducting OR is an appropriate use of scarce resources. A supportive environment is essential to nurture newly formed technical capacity built through a week-long workshop, and this environment is more likely when an NGO has strong and supportive leadership. Only two NGOs (Prosalud and CHAG) moved beyond the

Table 1.

\section{Sustainability studies conducted through FSCBI}

\begin{tabular}{|c|c|}
\hline Type of Study & Institution and Country \\
\hline \multirow[t]{3}{*}{ Cost diagnostic } & Bolivia: APSAR \\
\hline & $\begin{array}{l}\text { Ghana: Christian Health Association of Ghana } \\
\text { (CHAG) }\end{array}$ \\
\hline & Kenya: Chogoria Hospital \\
\hline \multirow[t]{2}{*}{$\begin{array}{l}\text { Sustainability } \\
\text { diagnostic }\end{array}$} & $\begin{array}{l}\text { Bolivia: Prosalud, Center for Research, } \\
\text { Education and Services (CIES) }\end{array}$ \\
\hline & Ghana: CHAG \\
\hline \multirow[t]{2}{*}{ Break-even analysis } & Bolivia: Prosalud \\
\hline & $\begin{array}{l}\text { Uganda: The AIDS Support Organization } \\
\text { (TASO) }\end{array}$ \\
\hline \multirow[t]{5}{*}{ Income generation } & $\begin{array}{l}\text { Bangladesh: Population Services and Training } \\
\text { Centre (PSTC) }\end{array}$ \\
\hline & $\begin{array}{l}\text { Ghana: Ghana Social Marketing Foundation } \\
\text { Enterprises Limited (GSMFEL) }\end{array}$ \\
\hline & India: Child in Need Institute (CINI) \\
\hline & $\begin{array}{l}\text { Honduras: Honduran Family Planning } \\
\text { Association (ASHONPLAFA) }\end{array}$ \\
\hline & $\begin{array}{l}\text { Nepal: Chhetrapati Family Welfare Center } \\
\text { (CFWC) }\end{array}$ \\
\hline
\end{tabular}

Source: Bratt, Homan, Janowitz, and Foreit 2007. 


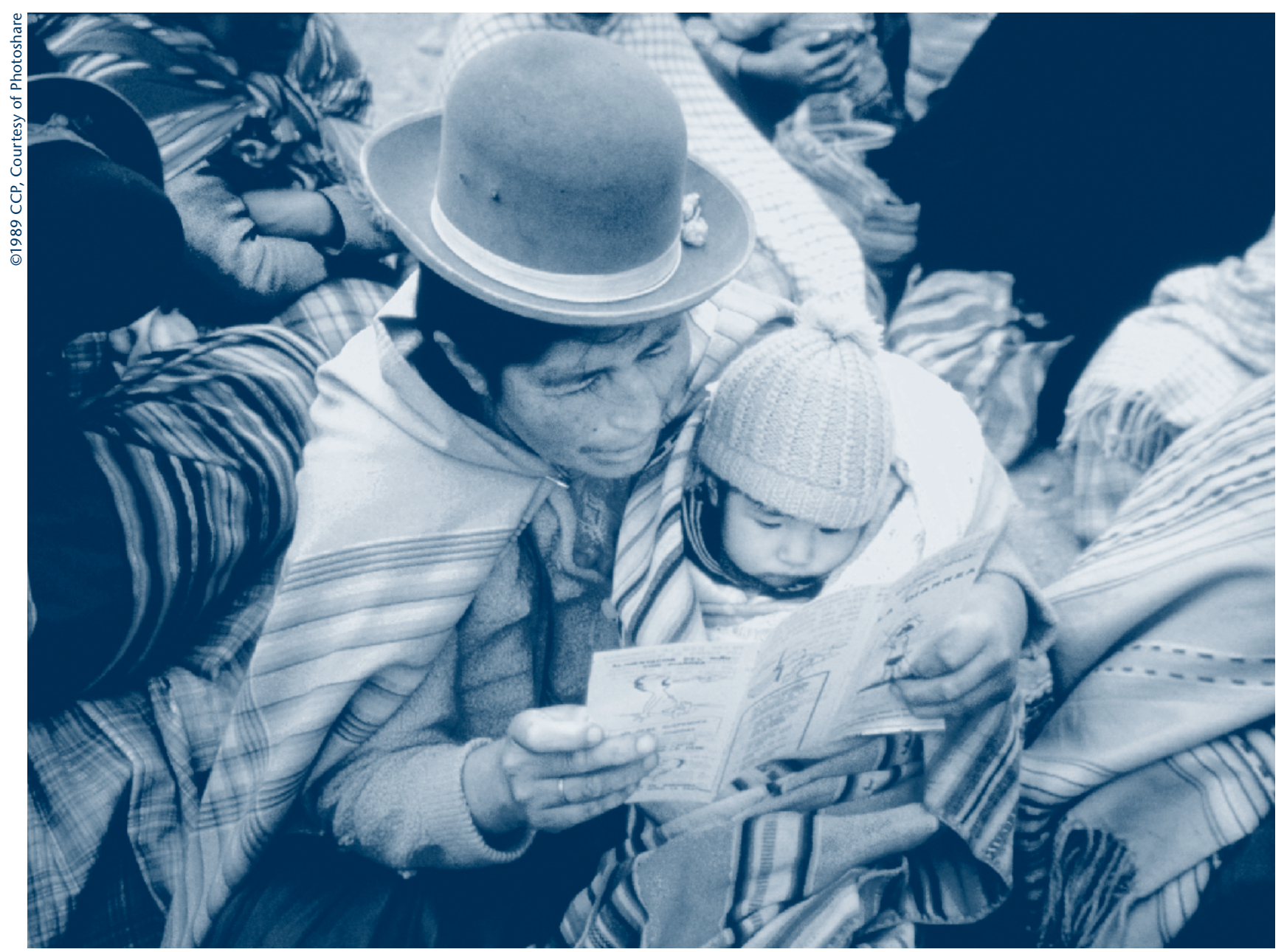

The Association of Rural Health Providers, a participant in the FSCBI, works in rural areas of Bolivia.

first round of studies to carry out second-generation OR projects. In both cases, substantial technical and financial assistance was still required to develop and implement these studies.

\section{Management support and commitment are critical to maintain momentum}

Ultimately, organizational capacity resides in individuals - who are, of course, free to leave the institution at any time for better job opportunities. Thus it is criti- cal to ensure that NGO managers participate in and support capacity building in financial analysis so that when trained employees leave, their skills are retained within the institution. Some of the NGOs that participated in the FSCBI lost key staff during project implementation, which stopped the project or reduced the likelihood that results would be used. In Bolivia, for example, Prosalud's champion of testing alternative marketing plans left the organization and was replaced by new staff who assigned a lower priority to developing new marketing strate- gies. As a consequence, one of two second-generation OR projects was dropped, and the other was completed with little direct involvement of Prosalud senior management. Without management support and a mechanism to retain or replace the skills of departing employees, it is difficult to achieve a successful long-term relationship, such as the earlier partnership between INOPAL and CEMOPLAF.

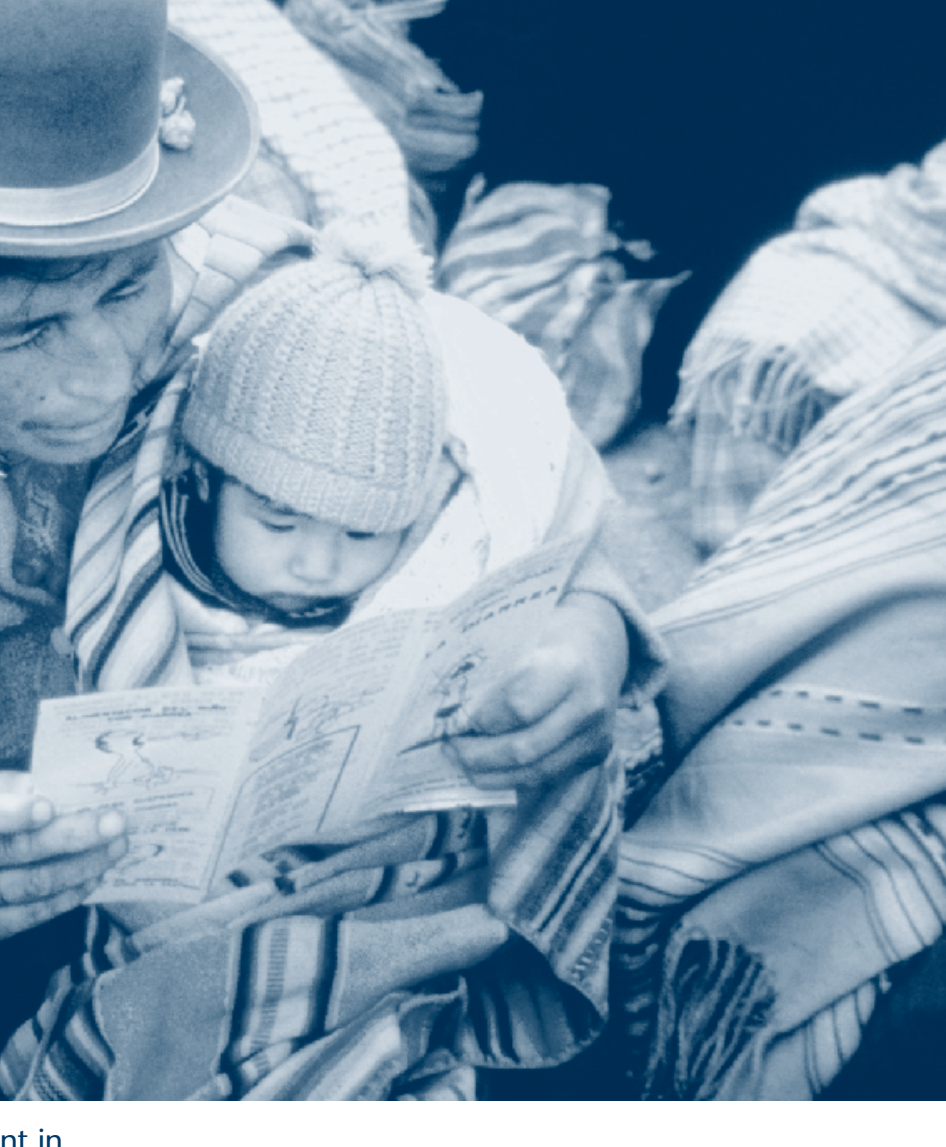




\section{Box 2}

\section{Building strength: Factors in NGO success}

NGOs are valuable community and program resources because they offer affordable local expertise, links to the community, and knowledge of their local environment (Population Council and CMS 2002). Yet few NGOs are strategically positioned to deal with the recent trend toward economic reform and decentralization of public-sector funds-even when such reforms are designed to foster partnerships between government services and private-sector entities, like the Sector Wide Approach (SWAp) programs in Africa.

A review of 16 reproductive health NGOs in Uganda, for example, identified typical NGO operational problems. The review found that almost half had no strategic plan, and only one NGO had conducted a critical assessment of the competitive and economic environment. Most were overdiversified, offering between 10 and 30 reproductive health products and services; few of the Ugandan NGOs had a clear understanding of their relative advantages versus those of competitors (Mugisha, Birungi, and Askew 2005). Most NGOs lack sufficient revenue streams to leverage funding from local entities, such as banks (Population Council and CMS 2002).

Participants at a 2002 meeting on NGO sustainability reviewed characteristics of successful NGOs, such as Ecuador's CEMOPLAF. The review showed that NGOs with the greatest potential for sustainability share specific characteristics:

- Decentralized leadership.

- Diversified funding sources, including microcredit enterprises, capital investments in real estate, and strategic pricing.

- Use of information systems for decisionmaking.

- Accrual of profits to subsidize social missions and programs for the poor.

- Strong human resource management.

Meeting participants agreed that strategic financial planning and examination of market opportunities are critical to help NGOs survive, compete, and approach sustainability during an era of economic constraint (Population Council and CMS 2002).

\section{Projects that attempted to generate additional income had little success}

Cost control and income generation are the two main paths to sustainability available to NGOs (see Box 2 for characteristics of successful NGOs). The organizations working with FSCBI tended to show more interest in generating income than in controlling costs, but their incomegeneration interventions failed to produce much additional revenue. Instituting systematic screening 4 by ASHONPLAFA in Honduras, for example, identified only a small demand for additional family planning and reproductive health services, which suggests that income-generation efforts should focus on other types of services, such as dental care, optometry services, and internal medicine. In the CINI and CFWC studies (India and Nepal), additions to revenue were very small, indicating that large increases in volume would be needed to make any substantial impact on sustainability (Das et al. 2007; Shrestha et al. 2007).

\footnotetext{
${ }^{4}$ Systematic screening is a technique for identifying and meeting clients' unmet needs for health care services. Providers use a standardized instrument, generally a checklist or set of questions, to determine whether a client needs services other than the one for which she came-such as reproductive health services, immunization, or other services. The providers then offer additional services during the same visit or make an appointment or referral for services that cannot be provided immediately (Foreit 2006, online at http://www. popcouncil.org/pdfs/frontiers/pbriefs/ Sys_Scrn_brf.pdf).
} 
NGOs find it difficult to compromise social objectives to improve sustainability

NGOs with a strong sense of social mission often resist the idea of earning profits, even if the profits are used to subsidize other activities with purely social objectives. For example, Prosalud's Social Marketing program originally was established to pursue a mixture of social and financial objectives. A break-even study conducted in 2007 identified several different products, including male and female condoms and multivitamins, targeted at commercial-sector outlets, NGOs, and rural clients. Analysis showed that contribution margins were negative for several products; in some cases, negative margins were due to high product costs, and in others, they were due to low prices to ensure affordability for the poor. The FSCBI study concluded that Prosalud's overall social mission would be advanced more effectively by a marketing program that focused on profit maximization and cross-subsidy of family planning services (Bratt, Riveros, and Cabrera 2007). The analysis of NGO sustainability in Uganda had similar findings: three-quarters of the organizations studied had only a limited perspective of the range of potential clients, including the government. The authors conclude that Ugandan NGOs must act quickly to orient themselves to the new opportunities offered through health care decentralization, and that the government and donors must work with the NGOs to make use of the unique services that NGOs offer (Mugisha, Birungi, and Askew 2005).

\section{Donor expectations for NGO financial sustainability are not always realistic}

Donors encourage financial sustainability while simultaneously demanding that NGOs increase the number of services provided to the poor. However, serving the poor is a social mission that will never be self-sustaining because the poor are unable to cover the full costs of their care. The best expectation is that NGOs will cross-subsidize some services for the poor through resources earned from profitable services. However, donors often fail to support these profit-making services because they benefit the poor only indirectly. Several of the organizations attending the sustainability workshops were severely constrained by government and donor demands that they increase financial sustainability while keeping fees low or increasing the number of the services provided to the poor. These unrealistic demands prevented organizations in Bangladesh, Ghana, and Nepal from increasing cost recovery.

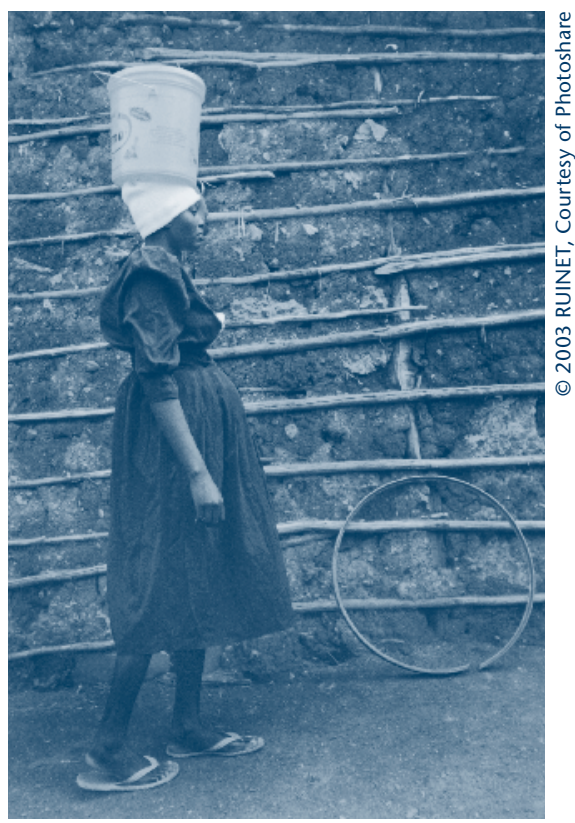

Kenya's Chogoria Hospital worked with the FSCBI to assess the costs of selected reproductive health services.

\section{Organizations sometimes continue to support ineffective sustainability interventions despite negative findings}

It is commonly assumed that utilization follows naturally from a successful intervention. However, in the FSCBI experience, this was not always the case. For example, in the case of GSMFEL in Ghana, sales of complementary (paired) products had no positive effect on revenues, but training was continued because it could be done at no cost to the organization, 
and program decisionmakers continued to believe in the efficacy of the intervention, despite the negative results (Bruce et al. 2006). In Honduras, a systematic screening intervention was scaled up in spite of inadequate implementation (only 11\% of clients were actually screened, although those clients received about 25\% more services than clients who were not screened) (Vernon et al. 2005). Training in financial research and analysis cannot result in organizational sustainability unless senior managers have a strong understanding of the purpose and value of these skills.

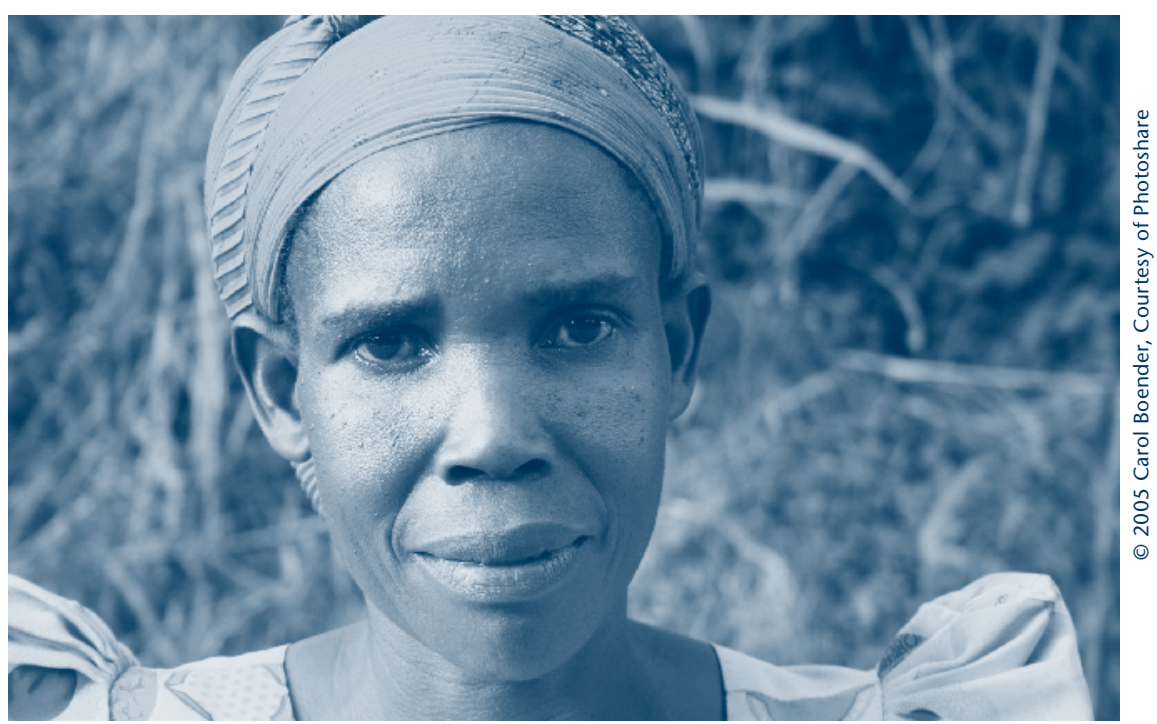

TASO works to improve the live of HIV-positive people and their families in Uganda, such as this widow, who helps care for 18 children orphaned by AIDS.

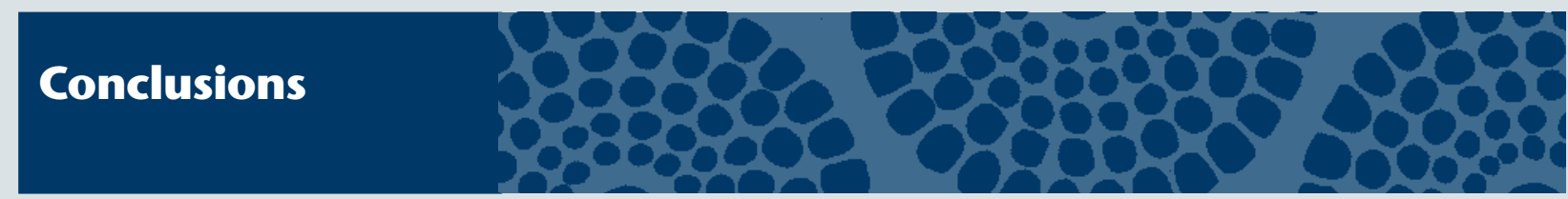

The experience of the FSCBI demonstrated the feasibility of training multidisciplinary teams of NGO staff to conduct sustainability-related OR. However, the research also highlighted several challenges that must be addressed in order to ensure durable capacity in this area. It is vital that managers and staff of NGOs (a) have the opportunity to conduct OR on financial sustainability, (b) maintain knowledge and commitment through organization-wide training to allow for staff turnover, and (c) balance the need to serve disadvantaged groups while generating profits to subsidize service to the poor.

Within NGOs, the greatest challenge is creating a "culture" of generating evidence through OR to guide strategies for sustainability, in which program managers (a) know that OR can help to improve decisions for ensuring financial sustainability, (b) can access the necessary technical expertise to carry out sustainability-related OR, and (c) apply the results of the research when making decisions within their programs. The FSCBI represented an important first step toward building necessary technical expertise, but similar efforts are needed to strengthen the capacity of program managers to recognize researchable problems and use research results appropriately. 
The Population Council conducts research worldwide to improve policies, programs, and products in three areas: HIV and AIDS; poverty, gender, and youth; and reproductive health.

The Frontiers in Reproductive Health Program (FRONTIERS) applies systematic research techniques to improve delivery of family planning and reproductive health services and influence related policies. FRONTIERS is funded by the U.S. Agency for International Development (USAID) and led by the Population Council in collaboration with Family Health International.

Frontiers in Reproductive Health Program (FRONTIERS) Population Council 4301 Connecticut Avenue, NW, Suite 280

Washington, DC 20008

Telephone: (202) 237-9400

Facsimile: (202) 237-8410

E-mail: publications@popcouncil.org

www.popcouncil.org/frontiers

This publication is made possible by the generous support of the American people through the United States Agency for International Development (USAID) under the terms of Cooperative Agreement No. HRN-A-0098-00012-00. The contents are the responsibility of the FRONTIERS Program and do not necessarily reflect the views of USAID or the United States Government.

\section{(c) 2008 The Population Council, Inc.}

This publication may be reproduced in whole or in part without permission of Population Council provided full source citation is given and the reproduction is not for commercial purposes. 